\title{
Configurações
}

Revista de sociologia

\section{Quanto tempo para aceder ao mercado de trabalho? A inserção profissional dos diplomados do ensino superior no dealbar da recessão*}

How much time to enter the labour market? The employability of higher education graduates at the dawn of the recession Combien de temps pour entrer dans le marché du travail ? L'insertion professionnelle des diplômés de l'enseignement supérieur à l'aube de la récession

\section{Miguel Chaves e César Morais}

\section{OpenEdition}

\section{Edição electrónica}

URL: http://journals.openedition.org/configuracoes/3293

DOI: $10.4000 /$ configuracoes.3293

ISSN: 2182-7419

\section{Editora}

Centro de Investigação em Ciências Sociais

Edição impressa

Data de publição: 27 Junho 2016

Paginação: 231-251

ISSN: 1646-5075

\section{Refêrencia eletrónica}

Miguel Chaves e César Morais, « Quanto tempo para aceder ao mercado de trabalho? A inserção profissional dos diplomados do ensino superior no dealbar da recessão* », Configurações [Online], 17 | 2016, posto online no dia 30 junho 2016, consultado o 01 maio 2019. URL : http:// journals.openedition.org/configuracoes/3293 ; DOI : 10.4000/configuracoes.3293 
Chaves, Miguel; Morais, César - Quanto tempo para aceder ao mercado de trabalho?

A inserção profissional dos diplomados do ensino superior no dealbar da recessão.

Configurações, vol. 17, 2016, pp. 231-251

\title{
Quanto tempo para aceder ao mercado de trabalho? A inserção profissional dos diplomados do ensino superior no dealbar da recessão*
}

\author{
MIGUEL CHAVES** \\ CICS.NOVA, Universidade Nova de Lisboa \\ CÉSAR MORAIS*** \\ CICS.NOVA, Universidade Nova de Lisboa
}

\section{Resumo}

Este artigo perspetiva a inserção profissional de graduados do ensino superior, estimando e analisando o intervalo temporal entre a conclusão do curso e a obtenção de um emprego. Um questionário aplicado em 2010 a uma amostra representativa dos licenciados na Universidade de Lisboa e na Universidade Nova de Lisboa revela distintos tempos de inserção, tanto no acesso a um primeiro emprego, como a um emprego ajustado ao nível e à área de formação. Os dados indicam que os desiguais ritmos de incorporação no mercado de trabalho são claramente marcados pelas diferentes áreas de formação, ao mesmo tempo que parecem ser pouco clivados pelas diferenças associadas às origens sociais (capital económico e escolar da família de origem). Neste sentido, sugere-se que pelo menos uma parte do segmento universitário público desempenhava, no momento que antecedeu o agravamento da conjuntura económica resultante da intensificação das políticas de austeridade, um efetivo papel de nivelamento social, que se manifestava no momento da transição dos diplomados para o mercado de trabalho, papel que tem sido pouco enfatizado pela sociologia portuguesa.

Palavras-chave ensino superior, tempos de inserção profissional, nivelação e reprodução de desigualdades.

\footnotetext{
* Este artigo foi financiado por Fundos Nacionais através da Fundação para a Ciência e Tecnologia (FCT), no âmbito do projeto Percursos de inserção dos licenciados: relações objetivas e subjetivas com o trabalho (PTDC/CS-SOC/104744/2008), sediado no Centro de Estudos em Sociologia da Universidade Nova de Lisboa (CESNOVA), e coordenado por Miguel Chaves.

* Docente na Faculdade de Ciências Sociais e Humanas, da Universidade Nova de Lisboa e investigador no CICS.NOVA. Email: miguel.chaves@fcsh.unl.pt.

*** Investigador no CICS.NOVA. Email: cesar.morais@mail.telepac.pt.
} 


\section{Abstract \\ How much time to enter the labour market? The employability of higher education graduates at the dawn of the recession}

This article puts into perspective the employability of higher education graduates, estimating and analysing the time span between ending the course and getting a job. A questionnaire applied in 2010 to a representative sample of graduates at the Universidade de Lisboa and the Universidade Nova de Lisboa shows distinct employability times, both in the access to a first job, as to a job adjusted to the education level or training area. The data suggests that the unequal rhythms of incorporation in to the labour market are clearly marked by the different areas of academic training, at the same time they appear to be only slightly cleaved by the differences associated with social backgrounds (economic and educational capital of the family of origin). In this sense, it is suggested that at least part of the public university segment played, at the moment preceding the deterioration of the economic conjuncture resulting from the intensification of austerity policies, an effective role of social levelling, which manifested itself on the transition of graduates to the labour market, a role that has been insufficiently emphasised by Portuguese sociology.

Keywords: higher education, temporality of employability, levelling and reproduction of inequalities.

\section{Résumé}

Combien de temps pour entrer dans le marché du travail ? L'insertion professionnelle des diplômés de l'enseignement supérieur à l'aube de la récession

Cet article analyse l'insertion professionnelle des diplômés, en estimant l'espace temporel entre la conclusion de leur formation supérieure et l'obtention d'un emploi. Un questionnaire proposé en 2010 à un échantillon représentatif des diplômés de l'Université de Lisbonne et de l'Université Nova de Lisbonne révèle les différents temps d'accès au premier emploi, ainsi qu'à un emploi ajusté au niveau et au domaine de formation. Les données indiquent que les rythmes inégaux d'incorporation dans le marché du travail sont clairement affectés par les différents domaines de formation, mais semblent être peu clivés par les différences d'origines sociales (capital économique et scolaire de la famille d'origine). En ce sens, il est suggéré qu'au moins un segment de l'université publique a joué un rôle effectif de nivellement social, à l'époque qui a précédé l'aggravation de la situation économique intensifiée par les politiques d'austérité. Ce rôle se manifestait au moment de la transition des diplômés vers le marché du travail. Il a été, jusqu'à présent, peu souligné par la sociologie portugaise.

Mots-clés: enseignement supérieur, temps d'insertion professionnelle, nivellement et reproduction des inégalités. 


\section{Introdução: duas questões basilares em torno dos "tempos de inserção profissional"}

Têm-se vindo a multiplicar, nas últimas décadas, os ângulos de abordagem da problemática da inserção profissional dos diplomados do ensino superior, seja esta recoberta pelo termo "inserção profissional" ou por expressões análogas, como, por exemplo, "transição ao trabalho" ou "entrada na vida ativa". Não obstante as suas especificidades, estas têm em comum o facto central de se debruçarem sobre a incorporação dos diplomados na estrutura produtiva. $\mathrm{O}$ "modo como os graduados se distribuem no mercado de trabalho", a "relação entre estrutura ocupacional e sistema formativo", o "(des)ajustamento entre procura e oferta de mão-de-obra", a "socialização profissional, as estratégias, recursos e aspirações dos recém-formados" são apenas alguns exemplos da multiplicidade de temas suscitados por este domínio de análise, pluralidade que se mantém, mesmo se nos circunscrevermos à sociologia portuguesa (Alves, 2009; M. Alves, 2007; Chaves, 2010; Marques, 2006).

Apesar desta pluralidade temática, com implicações definicionais, revemo-nos na posição de Natália Alves (2009: 21-23) ao sugerir que, em termos minimais, a inserção pode ser descrita e analisada como uma sucessão de posições no mercado de trabalho. Trata-se de uma aceção de cariz topológico que tem a virtude de nos colocar diante de dois requisitos nucleares na análise do processo. Primeiro, face à necessidade de se identificar, em pormenor, as posições ocupadas pelos indivíduos ao longo da sua dinâmica de incorporação no mercado de trabalho, desiderato para o qual se recorre, geralmente, às dimensões utilizadas nas estatísticas do emprego (e.g. "situação perante a atividade"; "tipo de contrato de trabalho"; "profissão"; ou "rendimento"), conjugando-as com outras usadas em diversos inquéritos à inserção de âmbito nacional ou internacional (e.g., "satisfação com a profissão"; "adequação da formação à profissão"; ou "modos de acesso ao emprego").

Em segundo lugar, esta aceção de inserção obriga-nos a mensurar o tempo necessário à obtenção de uma atividade profissional com determinadas propriedades específicas, como, por exemplo, o facto de se adequar ao nível ou à área de formação; de apresentar alguma estabilidade' ${ }^{1}$ ou, simplesmente, de "ser remunerada" (distinguindo-se assim, por exemplo, de estágios não-remunerados, tenham estes ou não um estatuto curricular).

1 A questão da estabilidade relativa da posição alcançada está presente em duas das mais relevantes propostas de delimitação da "fase de inserção profissional", distinguindo-a de momentos anteriores e posteriores da trajetória. Referimo-nos à proposta de Vernières (1997:19), que faz depender o final da inserção da obtenção de uma "posição estabilizada" no mercado de trabalho, assim como ao balizamento mais subjetivista de Vincens (1997), que considera que o "final do período de inserção" corresponde ao terminus de uma fase orientada para a procura de emprego (ou para a realização de estudos destinados a permitir o acesso a um outro emprego), com a crença de que se dispõe de um emprego durável, na medida em que não se procura outro no futuro. Uma reflexão sobre a delimitação temporal do processo de inserção profissional pode ser consultada em Alves (2010). 
O presente artigo debruça-se sobre o segundo género de problemas, que remetem para os "tempos de inserção". Em primeiro lugar, iremos confrontar-nos com o tempo de acesso ao primeiro emprego, ou seja, com o instante que Natália Alves, inspirada em Giret (2000) e Rose (1998), designa por primo inserção. A primo inserção pode ser definida como o processo de negociação do título escolar que a maioria dos diplomados leva a cabo no momento em que conclui os seus estudos e que culmina com o acesso a um primeiro emprego (Alves 2009:48). Neste sentido, procuraremos determinar o tempo que uma extensa população de licenciados portugueses demorou a obter trabalho e, simultaneamente, aferir se era significativo o número daqueles que, cinco anos após a obtenção de grau superior, ainda não tinham obtido qualquer atividade profissional. À análise da primo inserção seguir-se-á uma tentativa de determinar o tempo necessário para se alcançar um emprego ajustado ao "nível de instrução superior” e à “área de formação”, sendo talvez desnecessário acrescentar que o acesso a qualquer destas situações se afigura mais exigente e diferenciador do que o acesso a uma "mera" atividade remunerada

Procuraremos, finalmente, aferir em que medida duas dimensões do capital escolar - "área de formação" e "classificação final de curso" -, por um lado, e dois aspetos diretamente associados às origens sociais - "nível de instrução" e "classe social da família de origem" -, por outro, contribuem para explicar a maior ou menor celeridade no acesso ao primeiro emprego e a empregos ajustados tanto ao nível como à área de formação. Ao contrastar entre si aqueles pares de variáveis pretendemos, sobretudo, avaliar se o tempo de acesso a posições profissionais é clivado apenas por variáveis associadas ao capital escolar, ou se será também marcado, de forma notória, por diferenças que se prendem com o volume de capital da família de origem, indiciando assim a permanência de eventuais (e porventura significativas) desigualdades sociais na transferência dos graduados para o mercado de trabalho, mesmo entre indivíduos que, como é o caso, provêm das mesmas universidades.

O último problema abordado converge, de forma direta com uma interrogação sociológica mais ampla: em que medida a frequência do ensino superior opera como uma instância de atenuação dos processos de reprodução das desigualdades sociais junto daqueles que o concluem e que procuram inserir-se no mercado de trabalho? Abordar a questão da reprodução/atenuação das desigualdades entre diplomados centrando-a no momento da inserção profissional, e não no instante do acesso ao sistema universitário, observando quem nele ingressa e quem dele fica afastado ou o modo como se distribuem os ingressados pelos diferentes subsistemas ou áreas de formação (Alves, 2009; Almeida et al., 2003; Balsa et al., 2001; Chaves, 2010; Chaves e Nunes, 2011; Mauritti, 2003; Morais, 2012; Cruz e Cruzeiro, 1995; Costa e Lopes, 2010; Martins, Mauritti e Costa, 2005), constitui um exercício raramente realizado no âmbito da sociologia portuguesa, embora tenha já merecido atenção além-fronteiras 
(e.g., Hout 1988; Torche 2011; Bernardi 2012; Bukodi e Goldthorpe 2011; Mastekaasa 2011; Opheim 2007; Triventi 2011). Em artigo recente tivemos oportunidade de reportar que, em grandes linhas, os resultados obtidos sobre estas matérias opõem, sobretudo, os estudos europeus aos norte-americanos (Chaves e Morais, 2014).

Este universo corresponde à totalidade dos licenciados de duas universidades públicas lisboetas - a Universidade de Lisboa (UL) e a Universidade Nova de Lisboa (UNL) - que concluíram os seus cursos no ano letivo de 2004-05. Se tivermos em mente a extensão dos universos geralmente abrangidos nos inquéritos à inserção dos diplomados realizados em Portugal somos forçados a reconhecer que nos encontramos perante uma população relativamente ampla. Com efeito, desde a inquirição inédita realizada pelo ODES (2001) à totalidade dos licenciados portugueses, os apuramentos desta natureza passaram a ser realizados individualmente, por cada estabelecimento de ensino. As escolas produzem dados sobre os seus próprios graduados que, ao resultarem de indicadores e de questões díspares, não podem ser agregados numa base comum, limitando sobremaneira a acuidade da informação disponível (Chaves, Morais e Nunes, 2009). Mais pertinente ainda seria a articulação dessa informação com a disponibilizada em bases de dados internacionais, em alguns casos já produzidas, e que surgem bem identificadas em artigo recente de Raffe (2014).

\section{Opções metodológicas e variáveis em análise}

Os dados analisados resultaram de questionário administrado telefonicamente a uma amostra aleatória simples de 1004 indivíduos, extraída de uma base de sondagem constituída pela totalidade dos licenciados da UL e da UNL que obtiveram o seu diploma em 2004-05 (N=4290). Trata-se de uma coorte de graduados que concluiu as suas licenciaturas num modelo pré-Bolonha, tendo estas uma duração compreendida entre 4 a 5 anos. A inquirição decorreu entre Novembro de 2010 e Janeiro de 2011. O erro amostral máximo estimado situa-se nos 2,71\% para um nível de confiança de 95\%. O inquérito cobriu um conjunto de aspetos relativos ao percurso profissional dos inquiridos, um, três e cinco anos após a conclusão da licenciatura.

$\mathrm{Na}$ elaboração do presente artigo mobilizaram-se três variáveis dependentes, todas de natureza temporal. A primeira avalia o período que dista entre a conclusão da licenciatura e a obtenção de um trabalho remunerado; a segunda procura determinar o tempo necessário à obtenção de uma atividade profissional ajustada ao nível de instrução; a última variável reflete o tempo despendido na obtenção de uma ocupação ajustada à área de formação. A construção destas variáveis partiu da resposta às seguintes três questões: Após a licenciatura, a) "quantos meses demorou a encontrar um emprego ou trabalho remunerado?"; b) "quantos meses demorou a encontrar uma atividade profissional 
que, pelo menos em parte, considera que só pode ser convenientemente executada por alguém com formação superior?"; c) "quantos meses demorou a encontrar uma atividade profissional que, pelo menos em parte, considera que só pode ser convenientemente executada por alguém com a sua licenciatura ou licenciaturas próximas?".

As respostas obtidas em qualquer destas variáveis, em número de meses, foram posteriormente agregadas em cinco categorias: "0 meses (Imediato)”, “1 a 6 meses", "7 a 12 meses”, "mais de 12 meses” e, por fim, a categoria "nunca encontrou”, que reúne aqueles que, ao fim de cinco anos, não tinham ainda encontrado qualquer trabalho com as prerrogativas suprarreferidas.

No sentido de se responder às questões avançadas no ponto anterior mobilizaram-se quatro variáveis independentes: "área de formação", "classificação final de curso", "nível de instrução da família de origem" e "classe social da família de origem".

Para a construção da variável área de formação agrupou-se a quase centena de cursos que constituem a oferta formativa das duas universidades em análise em dez domínios formativos, tendo por base a Classificação Nacional de Áreas de Educação e Formação ${ }^{2}$. As “Artes e humanidades” reúnem o maior número de graduados (21,4\%), seguindo-se "Saúde" (12,7\%), “Ciências físicas" (12\%), "Educação" (10\%), "Direito" (9,7\%), "Ciências da vida" (8,6\%), "Ciências sociais e jornalismo" (7,7\%), "Economia e gestão” (6,7\%), "Matemática, estatística e informática” (6,5\%) e "Engenharias industriais e construção" (4,9\%).

As classificações finais de curso, obtidas através da declaração dos inquiridos, foram agrupadas em três patamares avaliativos: "até 13 valores", "14 e 15 valores" e "16 ou mais valores".

Para a elaboração da variável classe social da família de origem recolheram-se dados socioprofissionais tanto acerca do pai como da mãe dos licenciados. Foram depois determinados os seus lugares de classe individuais de acordo com a matriz ACM (Almeida et al., 1988), nos termos propostos por Machado et al. (2003: 51). Essas posições individuais foram posteriormente combinadas num índice familiar de classe, no qual se atribuiu ao agregado a classe do ascendente mais capitalizado, independentemente do género ou de qualquer outra característica (Alves, 2009; Machado et al., 2003). A aplicação desta tipologia permitiu apurar que a maior parte dos licenciados na UL e UNL são originários dos “Empresários, Dirigentes e Profissionais Liberais” (33,3\%) e dos "Profissionais Técnicos e de Enquadramento" (31,5\%), o que revela um nítido efeito de sobrerrepresentação das classes mais capitalizadas na população analisada, quando confrontada com a composição de classe da população portuguesa (Chaves e Morais, 2014) . $^{3}$

2 Para uma explanação detalhada dos procedimentos adotados, cf. Morais (2012: 172-76).

3 A sobrerrepresentação destas duas categorias de classe entre as famílias que constituem a nossa população torna-se evidente se a compararmos com as posições de classe da população portuguesa 
Por fim, o capital escolar do agregado familiar foi ventilado de acordo com as categorias do sistema oficial de graus de ensino, utilizando-se o nível de instrução do progenitor que atingiu o patamar de escolaridade mais elevado, ou seja, replicando-se o procedimento de síntese utilizado na construção da variável classe social da família de origem.

\section{Indícios de celeridade na primo inserção e no acesso a um emprego ajustado ao nível e à área de formação}

Basta observar o Quadro 1 para se constatar que, para a maioria dos diplomados, a primo inserção decorreu de forma relativamente célere: $84,3 \%$ obtiveram um primeiro trabalho no período máximo de seis meses após a graduação. Inversamente, o número daqueles que não haviam alcançado qualquer posição no mercado de trabalho cinco anos após a conclusão do diploma era residual, não atingindo sequer o patamar de $0,5 \%$.

A incorporação veloz dos inquiridos no mercado de trabalho não constitui um dado inesperado, pois já havia sido ressaltada em estudos anteriores. Natália Alves (2009), por exemplo, observou, em relação aos licenciados da Universidade de Lisboa das coortes de 1994 a 1998 e depois de 1999 a 2003, que "a transição da Universidade para o trabalho continua a ser, para a maioria [...], um processo relativamente rápido e pouco complexo: ou começaram imediatamente a trabalhar ou o tempo de procura de emprego não excedeu os seis meses" (Alves, 2005: 95).

Além disso, é importante sublinhar que a grande maioria da população analisada se confrontou pela primeira vez com o mercado de trabalho em 2005 , ano em que a taxa de desemprego não ultrapassava os 7,6\% e, junto dos graduados do ensino superior, se quedava nos $6,2 \%$ (INE, 2015). Outros dados recolhidos no âmbito do nosso inquérito, ajudavam também a prever estes resultados: a percentagem de "desempregados" e de "inativos" era, respetivamente, de 7,5\% e 7\% um ano após a licenciatura, baixava para $3,1 \%$ e $2,5 \%$ no terceiro ano, e não ultrapassava os $2,5 \%$ e os $4,2 \%$ cinco anos volvidos sobre a obtenção do grau. 
Quadro 1

Tempos de acesso ao emprego entre licenciados UL e da UNL após a graduação (\% em coluna).

\begin{tabular}{|c|c|c|c|}
\hline & $\begin{array}{c}\mathrm{N} .{ }^{\circ} \text { de } \\
\text { meses até } \\
\text { encontrar } \\
\text { um emprego }\end{array}$ & $\begin{array}{c}\text { N. }{ }^{\circ} \text { de meses até } \\
\text { encontrar um } \\
\text { emprego adequado } \\
\text { ao nível de instrução }\end{array}$ & $\begin{array}{l}\text { N. }{ }^{\circ} \text { de meses até } \\
\text { encontrar um emprego } \\
\text { adequado à área de } \\
\text { formação académica }\end{array}$ \\
\hline Imediato (0 meses) & 41,9 & 32,1 & 29,5 \\
\hline 1 a 6 meses & 42,4 & 35,0 & 32,6 \\
\hline 7 a 12 meses & 8,9 & 10,8 & 9,4 \\
\hline Mais de 12 meses & 6,4 & 14,6 & 14,4 \\
\hline Nunca encontrou & 0,4 & 7,5 & 14,1 \\
\hline Total & 100,0 & 100,0 & 100,0 \\
\hline Média (meses)* & 3,9 & 7,1 & 7,8 \\
\hline Desvio Padrão* & 6,9 & 11,5 & 12,7 \\
\hline
\end{tabular}

* Obtidos através do valor inteiro do número de meses, assumindo "0" para "Imediato (0 meses)" e desconsiderando a categoria "Nunca encontrou".

Fonte: Projeto Percursos Inserção Licenciados UL/UNL

Considerando agora os dois outros marcadores temporais de inserção analisados - "tempo necessário à obtenção de um trabalho considerado ajustado ao nível de formação superior" e "tempo necessário à obtenção de uma atividade considerada ajustada à área de formação" -, verificamos que também o acesso a posições com tais atributos parece ter ocorrido com celeridade para uma razoável maioria. Mais de 2/3 afirmam ter atingido uma posição compatível com o grau de escolaridade, e quase $2 / 3$ uma posição compaginável com a sua área formativa, num período que não ultrapassou os 6 meses após a conclusão do grau, embora o número daqueles que, ao fim de 5 anos, afiançou nunca ter conseguido atingir posições com esses predicados fosse já de 7,5\% no primeiro caso e de $14,1 \%$ no segundo.

É certo que os resultados devem ser interpretados tendo em conta os limites das questões e indicadores utilizados, baseados, neste caso, na perceção e avaliação dos próprios inquiridos; mas é também necessário reconhecer que tais dados são, em grande medida, reforçados por informações obtidas através de outros procedimentos. Se se utilizar, por exemplo, o critério preconizado pelo EUROSTAT (2009: 131-137) para avaliar o "ajustamento vertical" (Storen e Arnesen, 2007: 224), ou seja, o ajustamento entre as situações profissionais e o nível de instrução atingido, podemos afirmar que um ano após 
o diploma 79,1\% dos graduados inquiridos se encontravam numa situação de ajustamento, valor que aumentava para $87,2 \%$ cinco anos após a licenciatura. O critério utilizado pelo EUROSTAT prevê que as três primeiras categorias da International Standard Classification of Occupations (ISCO), equiparáveis aos três primeiros grupos profissionais da Classificação Portuguesa das Profissões de 2010 - os "Responsáveis do poder legislativo e de órgãos executivos, dirigentes, diretores e gestores executivos", os "Especialistas das atividades intelectuais e científicas” e, por fim, os “Técnicos e profissões de nível intermédio” - "incluem postos de trabalho tipicamente ocupados por graduados do ensino superior" (Rademacher e Leitner, 2009: 132).

Já no que concerne ao “ajustamento horizontal” (Storen e Arnesen, 2007), definível como o trabalho numa atividade que se encontra adequada à área de formação académica (idem: 202), os dados que apresentámos surgem de novo reforçados pelas respostas obtidas a outros quesitos do questionário. Em resposta à questão "Qual o grau de adequação das funções que desempenhavam no seu trabalho à área em que se licenciaram, um ano após a conclusão do grau", utilizando para o efeito uma escala de 10 pontos, $68 \%$ dos indivíduos atribuíram uma pontuação igual ou superior a 6 valores às funções exercidas ( $49 \%$ avaliaram-na, inclusive, entre os 8 e os 10 pontos, sinalizando assim que consideravam existir um grau de adequação muito elevado). Cinco anos após a licenciatura, ascendia a 76\% os que classificavam essas mesmas funções entre 6 e 10 e a $58 \%$ os que, para as avaliar, reservavam os 3 patamares mais elevados da escala (8-10).

Não é possível encerrarmos este bloco sem referir dois aspetos. Um primeiro, de ordem metodológica, no sentido de clarificar que a opção de avaliar os níveis de “(des)ajustamento horizontal”, recorrendo a exercícios de autoclassificação promovidos pelos inquiridos (ou seja, a opção que foi efetivamente utilizada), nos parece preferível ao uso da estratégia metodológica alternativa, que consiste em aferir se o sector de atividade económica é compaginável com o curso obtido. Esta última solução levanta-nos importantes reservas, pois numerosos cursos (ex. Gestão, Sociologia, Engenharia de Produção Industrial, etc.) permitem aos seus diplomados desenvolver atividades em diversos sectores de atividade sem que se torne possível determinar a priori quais aqueles em que se verifica adequação/desadequação entre as áreas de formação e o emprego.

Segundo esclarecimento: os dados que obtivemos para períodos posteriores, neste caso já só no âmbito da UNL, indiciam que o tempo necessário para a primo inserção se tem vindo a dilatar de forma sucessiva - os licenciados da UNL em 2008/09 demoraram, em média, três meses até encontrar um emprego depois de terminarem o curso, mas entre os licenciados em 2009/10 esse valor médio ascende a mais de 4 meses, para ultrapassar já os cinco meses no ano letivo seguinte (Chaves, Alves e Morais, 2013). Trata-se, sem dúvida, de uma tendência de adiamento que exige futuras análises, mas que, em linhas gerais, 
se ficará a dever à conjugação do efeito do Tratado de Bolonha no prolongamento dos estudos com a redução das oportunidades de trabalho registadas nos anos subsequentes à inquirição. De acordo com os dados do Instituto Nacional de Estatística, essa contração do emprego terá atingido o seu ponto mais crítico no primeiro trimestre de 2013 (INE, 2014).

\section{0 (reconhecido) potencial explicativo das áreas de formação}

Depois de documentarmos a celeridade da primo inserção e o ajustamento, também lesto, que se verifica, na maioria dos casos, da atividade profissional ao nível de instrução e à área de formação, iremos debruçar-nos sobre o segundo conjunto de questões enunciado de início. Serão as diferenças detetadas nos tempos de acesso ao emprego explicadas, em larga medida, pelas áreas de formação, como já foi documentado em estudos anteriores (Alves, 2000: 90; Cardoso et al., 2014: 25). Nesse caso que importância assumirá um outro recurso também de cariz académico - a "classificação final de curso" - na explicação dessas disparidades?

Por sua vez, assumirão as origens sociais - expressas nas variáveis "capital escolar" e "classe social da família de origem" (ambas indicativas de fatores estruturais situados a montante da entrada na universidade) - um papel relevante na diferenciação dos tempos de inserção, a ponto de tornar nítida a persistência de lógicas de reprodução das desigualdades no momento de transferência dos diplomados para a estrutura ocupacional, mesmo entre indivíduos que, como é o caso, provêm dos mesmos estabelecimentos de ensino superior?

Para respondermos a estas questões mobilizaremos apenas uma das três variáveis independentes: a "posição profissional considerada adequada à área de formação”. Do trio de variáveis apreciado no bloco anterior é a que prefigura a situação de ajustamento com contornos mais exigentes. Ao mesmo tempo é aquela que regista categorias de resposta mais dispersas, viabilizando assim a realização de testes estatísticos de associação, o que não sucede com qualquer das outras.

Como era expectável as áreas de formação revelam um potencial explicativo considerável no "ajustamento profissional horizontal”. Apesar do $V$ de Cramer ser pouco significativo $(0,222)$, as diferenças entre as áreas são fáceis de constatar se observarmos detalhadamente o Quadro 2, no qual os domínios formativos se apresentam sequenciados da esquerda para a direita, por ordem decrescente da percentagem de licenciados que declararam nunca ter alcançado um emprego adequado à sua área de formação ${ }^{4}$.

4 Note-se que a elevada dispersão de respostas dificulta, por mero efeito estatístico, a obtenção de um valor elevado no teste de $V$ de Cramer. Observando os resultados obtidos no Quadro, temos como muito provável que o $V$ de Cramer atingiria um valor notório se as 10 áreas de formação académica fossem agrupadas num número menor de "grandes áreas" de formação e educação. 
Distinguimos dois grandes grupos. O primeiro reúne as cinco áreas em que a percentagem de indivíduos que nunca alcançaram uma situação de ajustamento horizontal ao fim de cinco anos ultrapassa a média total $(14,1 \%)$. Referimo-nos a "Artes e humanidades", "Ciências da Vida”, "Ciências Físicas”, "Ciências sociais e Jornalismo" e "Engenharias industriais e de construção". O afastamento em relação ao valor médio torna-se particularmente nítido nas “Artes e humanidades" e nas "Ciências da Vida”, onde, respetivamente, 27,9\% e $19 \%$ dos inquiridos afiançaram nunca ter tido um emprego ajustado à sua formação, embora, na última área referida, o tempo médio para se encontrar um trabalho com essas características seja inferior àquele com que deparamos no caso das "Ciências Físicas" (7,5 meses), das "Ciências sociais" (11,3 meses) ou do "Jornalismo" (8,5 meses).

O segundo conjunto é formado pela "Matemática, estatística e informática”, "Economia e Gestão", "Direito", "Educação” e "Saúde”. Sobressai, neste grupo, a última área referida, por ser aquela onde o número de respondentes que nunca encontraram trabalho adequado à área de formação não atinge sequer $1 \%$. Este fato confirma a elevada procura de profissionais na área da Saúde, assim como a vincada adequação entre as funções desempenhadas e a posse de formação neste domínio, embora a situação dos cursos que o compõem - medicina; medicina dentária; higiene oral; prótese oral e ciências farmacêuticas - prefigurem, com toda a probabilidade, situações remuneratórias e de segurança contratual bem distintas.

Ainda no âmbito do cenário patente no Quadro 2 vale a pena chamar a atenção para o carácter especialmente atípico das áreas de "Educação" e de "Engenharias industriais e de construção", porquanto, em qualquer dos casos se verifica uma tendência paradoxal entre o número daqueles que consideram nunca ter tido um trabalho adequado à área de formação e o tempo médio que os indivíduos declaram ter demorado a alcançá-lo. Na área da Educação, embora a maioria alcance um emprego ajustado ao curso, os licenciados aí formados estão entre os que mais tardam a atingi-lo, demorando, em média, 11 meses. A estreita dependência deste contingente face ao universo da profissão docente explica grande parte da descoincidência: se no período em análise, e não obstante a elevada precariedade contratual, o grosso destes licenciados alcançava a profissão de professor, o acesso a esse meio era porém mediado por um concurso público que se iniciava apenas alguns meses depois do terminus da graduação.

Por seu lado, os licenciados em "Engenharias industriais e construção" registavam o paradoxo inverso ao observado na área de Educação: se o número daqueles que nunca haviam obtido um emprego ajustado ao seu curso cinco anos após a formação permanecia elevado (16,7\%), não deixava também de ser notória a percentagem daqueles que o obtiveram rapidamente. De fato, não ia além de 3,5 meses o tempo médio necessário para o alcançar. Trata-se de 
uma situação antagónica que só pode ser deslindada em pormenor mediante a realização de estudos específicos sobre este conjunto de licenciados - são disso exemplo os trabalhos de Rodrigues (1999) ou Marques (2006) -, mas onde parece já despontar a conjuntura negativa vivida no setor da construção.

\section{Quadro 2}

Período temporal até encontrar um emprego adequado à área de formação por área científica de formação (\% em coluna)

\begin{tabular}{|c|c|c|c|c|c|c|c|c|c|c|c|}
\hline & \multicolumn{10}{|c|}{ Área científica de formação } & \multirow[b]{2}{*}{ 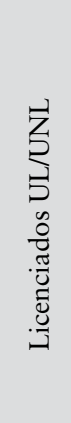 } \\
\hline & 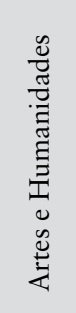 & $\begin{array}{l}\frac{\pi}{0} \\
j \\
\frac{\pi}{0} \\
0 \\
\frac{\pi}{0} \\
0 \\
0 \\
0 \\
0\end{array}$ & 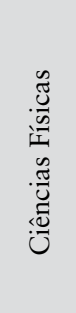 & 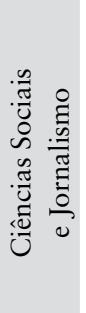 & 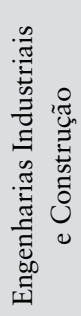 & 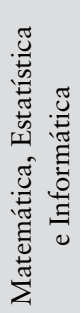 & 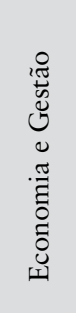 & 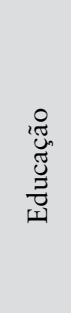 & $\begin{array}{l}\stackrel{\circ}{ \pm} \\
\stackrel{\Xi}{0} \\
0\end{array}$ & 苂 & \\
\hline $\begin{array}{l}\text { Imediato } \\
(0 \text { meses })\end{array}$ & 18,4 & 20,3 & 17,9 & 33,3 & 37,5 & 43,8 & 31,3 & 15,8 & 39,1 & 52,8 & 29,5 \\
\hline 1 a 6 meses & 19,4 & 35,4 & 30,4 & 25,0 & 37,5 & 25,0 & 44,7 & 44,2 & 34,8 & 43,2 & 32,6 \\
\hline 7 a 12 meses & 13,4 & 11,4 & 13,4 & 6,9 & 4,2 & 10,9 & 7,5 & 13,7 & 6,5 & 0,8 & 9,4 \\
\hline $\begin{array}{c}\text { Mais de } 12 \\
\text { meses }\end{array}$ & 20,9 & 13,9 & 21,4 & 18,1 & 4,2 & 9,4 & 7,5 & 18,9 & 15,2 & 2,4 & 14,4 \\
\hline $\begin{array}{c}\text { Nunca } \\
\text { encontrou }\end{array}$ & 27,9 & 19,0 & 17,0 & 16,7 & 16,7 & 10,9 & 9,0 & 7,4 & 4,3 & 0,8 & 14,1 \\
\hline Total & 100,0 & 100,0 & 100,0 & 100,0 & 100,0 & 100,0 & 100,0 & 100,0 & 100,0 & 100,0 & 100,0 \\
\hline $\begin{array}{c}\text { Média } \\
(\text { meses })^{*}\end{array}$ & 11,9 & 7,4 & 11,3 & 8,5 & 3,5 & 4,7 & 4,4 & 11,0 & 7,5 & 2,6 & 7,8 \\
\hline $\begin{array}{l}\text { Desvio } \\
\text { padrão* }\end{array}$ & 14,0 & 11,1 & 14,9 & 13,5 & 6,8 & 8,5 & 7,8 & 16,3 & 14,0 & 5,7 & 12,6 \\
\hline
\end{tabular}

Variáveis associadas (Qui-Quadrado significativo $\mathrm{p}=0,000$ e V de Cramer $=0,222$ ).

* Obtido através do valor inteiro do número de meses, assumindo " 0 " para "Imediato (0 meses)" e desconsiderando a categoria "Nunca encontrou".

Fonte: Projeto Percursos Inserção Graduados UL/UNL 
Continuando a estimar a importância do capital escolar no processo de inserção, é possível constatar que também a classificação final de curso influi no tempo que os licenciados demoraram a alcançar uma posição profissional compatível com o seu curso. O Quadro 3 demonstra que o tempo necessário para se obter uma atividade "ajustada" sofre incrementos positivos à medida que a nota de licenciatura se eleva. Bastará observar que a proporção de indivíduos que, ao fim de cinco anos, considera não ter obtido um trabalho desse género $(6,9 \%)$ é quase três vezes menor junto dos licenciados que obtiveram as classificações mais elevadas do que diante do contingente que não ultrapassou os 13 valores $(19,8 \%)$. Diferença idêntica é obtida se tivermos em conta o número de meses necessário à obtenção de um emprego com essas características. O tempo médio foi de 4 meses para os graduados que atingiram classificações de "16 valores ou mais", duplicou entre os que alcançaram 14-15 valores, e atingiu um ápice de 9 meses junto daqueles que obtiveram classificações inferiores a 14 valores.

Cotejando o alcance explicativo das duas variáveis anteriores, verificamos que tanto o valor do $V$ de Cramer como os resultados dos Quadros 2 e 3 sugerem que "as classificações de final de curso" têm um impacto menos determinante do que o da área de formação. Não deixamos contudo de colocar a hipótese de que o fator "classificação final" assumiria um peso diferenciador mais significativo se nos circunscrevêssemos ao grupo de licenciados que se inscreveram no sector público (5 anos após a graduação, estes correspondiam a 30,9\% do total), uma vez que se torna aí mais frequente a figura do concurso público ${ }^{5}$, mecanismo de seleção em que as classificações académicas tendem a adquirir relevância acrescida. É igualmente de considerar a hipótese de que a maior tendência observada junto daqueles que obtêm classificações mais elevadas para prolongarem os estudos ter contribuído, também, para reduzir o potencial explicativo da variável "classificação", uma vez que se encontra associada a um adiamento na procura de trabalho.

5 A informação sobre o setor de atividade em que se inseriam os licenciados "empregados" resulta da aplicação da questão "Em que tipo de empresa ou organização trabalhava?”, que considera 5 categorias de resposta, a saber, "empresa privada em geral", "empresa privada unipessoal ou em nome individual", "empresa pública ou mista”, "organismo da administração pública”, ou "ONG/IPSS". 
Quadro 3

Período temporal até encontrar um emprego adequado à área de formação por classificação final de curso (\% em coluna).

\begin{tabular}{|l|c|c|c|c|}
\hline & \multicolumn{3}{|c|}{ Classificação final de curso } & \multirow{2}{*}{$\begin{array}{c}\text { Licenciados } \\
\text { UL/UNL }\end{array}$} \\
\hline & $\begin{array}{c}\text { Até } 13 \\
\text { valores }\end{array}$ & $\begin{array}{c}14 \text { e } 15 \\
\text { valores }\end{array}$ & $\begin{array}{c}16 \text { e mais } \\
\text { valores }\end{array}$ & \\
\hline Imediato (0 meses) & 23,3 & 28,8 & 47,3 & 29,4 \\
\hline 1 a 6 meses & 31,9 & 32,3 & 33,6 & 32,3 \\
\hline 7 a 12 meses & 10,3 & 10,7 & 3,8 & 9,6 \\
\hline Mais de 12 meses & 14,7 & 16,0 & 8,4 & 14,5 \\
\hline Nunca encontrou & 19,8 & 12,2 & 6,9 & 14,2 \\
\hline Total & 100,0 & 100,0 & 100,0 & 100,0 \\
\hline Média (meses)* & 8,9 & 8,2 & 3,8 & 7,8 \\
\hline Desvio padrão* & 13,67 & 12,88 & 6,41 & 12,52 \\
\hline
\end{tabular}

Variáveis associadas (Qui-Quadrado significativo $\mathrm{p}=0,000$ e V de Cramer $=0,110$ ).

* Obtido através do valor inteiro do número de meses, assumindo " 0 " para "Imediato (0 meses)" e desconsiderando a categoria "Nunca encontrou".

Fonte: Projeto Percursos Inserção Graduados UL/UNL

\section{Indícios de nivelamento intrauniversitário no tempo de acesso ao emprego: uma hipótese a acompanhar}

Examinemos, por fim, em que medida as desigualdades de recursos situadas a montante da entrada no ensino superior se refletem nas temporalidades da inserção, sondando o impacto explicativo do Nível de instrução e da Classe social da família de origem no tempo necessário para os indivíduos alcançarem uma atividade profissional horizontalmente ajustada à sua área de formação.

A análise dos dados permite constatar que, embora não seja espúria, a relevância explicativa do nível de instrução dos progenitores é reduzida, facto que se torna notório tanto na baixa intensidade da correlação (o $V$ de Cramer não vai além de 0,089), como na observação dos resultados do Quadro 4. Apenas os diplomados que provêm de agregados com níveis de instrução superiores alcançam resultados que se distinguem dos obtidos pelas outras categorias. O número que declara nunca haver alcançado trabalho horizontalmente ajustado junto daqueles é de 9,9\%, ao passo que atinge sempre valores superiores a $16,5 \%$ nas demais situações. Além disso, o tempo médio necessário para se obter um trabalho que se considera possuir esse atributo é de 6,6 meses para 


\section{Quadro 4}

Período temporal até encontrar um emprego adequado à área de formação por nível de instrução do agregado familiar (\% em coluna).

\begin{tabular}{|l|c|c|c|c|c|c|}
\hline \multicolumn{5}{|c|}{ Nível de instrução do agregado familiar } \\
\hline
\end{tabular}

Variáveis associadas (Qui-Quadrado significativo $p=0,019$ e V de Cramer =0,089).

* Obtido através do valor inteiro do número de meses, assumindo " 0 " para "Imediato (0 meses)" e desconsiderando a categoria "Nunca encontrou".

Fonte: Projeto Percursos Inserção Graduados UL/UNL

os provenientes das categorias de instrução mais elevadas, ligeiramente inferior aos 7,8 meses que correspondem à média total. Em qualquer dos casos, as diferenças observadas são, como é fácil verificar, pouco intensas.

A correlação volta a ser pouco expressiva ( $V$ de Cramer de 0,088$)$ quando mobilizamos a Classe Social do agregado como variável explicativa (Quadro 5). Se os resultados indiciam que os indivíduos provenientes das classes que possuem um maior volume de capital global - "Empresários, Dirigentes e Profissionais Liberais" (EDL) e os "Profissionais Técnicos e de Enquadramento" (PTE) - acedem de forma mais célere a situações de ajustamento horizontal, as diferenças encontradas são, porém, ténues, fazendo-se apenas notar entre aqueles que afirmam nunca ter encontrado trabalho adequado à área de formação. Os EDL e os PTE registam, respetivamente, $11,4 \%$ e $10,1 \%$ de diplomados nessas circunstâncias, ao passo que a média total se situa na casa dos $14,1 \%$. 


\section{Quadro 5}

Período temporal até encontrar um emprego adequado à área de formação por classe social do agregado familiar ( $\%$ em coluna $)^{6}$.

\begin{tabular}{|c|c|c|c|c|c|c|}
\hline & \multicolumn{5}{|c|}{ Classe social do agregado familiar } & \multirow[b]{2}{*}{ 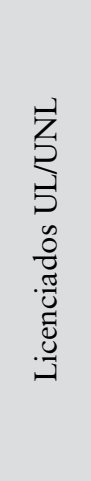 } \\
\hline & 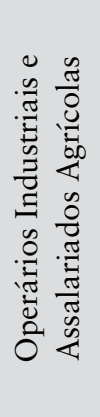 & 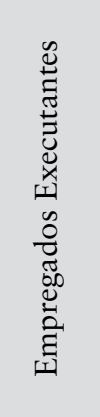 & 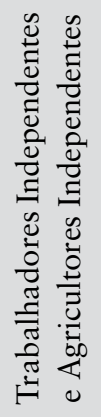 & 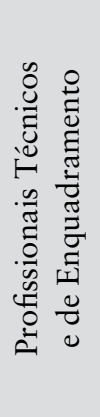 & 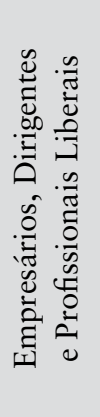 & \\
\hline Imediato ( 0 meses) & 23,0 & 25,9 & 33,8 & 29,1 & 31,3 & 29,0 \\
\hline 1 a 6 meses & 25,7 & 27,5 & 27,0 & 38,4 & 33,9 & 32,8 \\
\hline 7 a 12 meses & 14,9 & 10,6 & 9,5 & 8,3 & 8,5 & 9,4 \\
\hline Mais de 12 meses & 17,6 & 14,3 & 12,2 & 12,8 & 16,3 & 14,6 \\
\hline Nunca encontrou & 18,9 & 21,7 & 17,6 & 11,4 & 10,1 & 14,1 \\
\hline Total & 100,0 & 100,0 & 100,0 & 100,0 & 100,0 & 100,0 \\
\hline Média (meses)* & 10,4 & 8,6 & 6,6 & 6,4 & 8,6 & 7,9 \\
\hline Desvio padrão* & 14,1 & 13,3 & 10,8 & 9,9 & 14,6 & 12,7 \\
\hline
\end{tabular}

Variáveis associadas (Qui-Quadrado significativo $\mathrm{p}=0,025$ e V de Cramer $=0,088$ ). "Obtido através do valor inteiro do número de meses, assumindo " 0 " para "Imediato (0 meses)" e desconsiderando a categoria "Nunca encontrou".

Fonte: Projeto Percursos Inserção Graduados UL/UNL

É curioso verificar que é entre os "Empregados Executantes" (EE) que a percentagem daqueles que nunca desenvolveram atividades profissionais horizontalmente ajustadas é mais elevada, ascendendo a 21,7\%. Este valor duplica os números obtidos pelos descendentes dos agregados EDL, mas é também

6 Uma vez que o peso percentual reduzido dos Agricultores independentes (1,6\%) e Assalariados agrícolas $(1,6 \%)$ impedia o cumprimento dos requisitos dos testes estatísticos de associação e correlação, procedeu-se a uma agregação dessas duas classes. Como refere Firmino da Costa, esta tipologia permite "agregações de categorias, rearranjos classificatórios dos elementos de base da matriz ou, ainda, eventuais desdobramentos mais finos" de forma a manter as "possibilidades comparativas e adequação à especificidade dos objetos em estudo" (Costa, 1999: 230). 
superior ao dos indivíduos oriundos do Operariado, tendencialmente mais descapitalizados e mais distantes da cultura escolar. Não dispomos, no presente artigo, de condições para aprofundar o significado destes resultados. Levantamos contudo a hipótese de que os piores resultados obtidos junto dos EE, em contraste com os do Operariado, se poderão dever ao processo de sobre-selecção social que se verifica no acesso à universidade ser mais intenso junto dos segundos. Com efeito, na nossa população, o índice de recrutamento social junto do operariado é de 1, ao passo entre os EE ascende a 3 (Morais, 2012: 32$)^{7}$. Conjeturamos que a sobre-seleção operária se refletirá numa tendência para os diplomados originários desta classe obterem classificações em média mais elevadas do que os provenientes dos EE e na posse de um conjunto de competências relevantes no momento da procura de emprego, competências que se poderão traduzir, nomeadamente, na qualidade da performance realizada em entrevistas de seleção (Chaves, 2010). Obviamente, só fará sentido aprofundar estas ou outras hipóteses explicativas se as discrepâncias registadas entre filhos do operariado e descendentes dos EE forem ratificadas por estudos análogos.

Os dados apresentados neste artigo, centrados na primo inserção e nos tempos de acesso ao mercado de trabalho, vêm reforçar conclusões a que havíamos aportado em análises anteriores, nomeadamente num estudo onde se procurou aferir o peso explicativo das origens sociais no tipo de posições profissionais que estes mesmos diplomados ocupavam no mercado de trabalho, considerando, nesse caso, as variáveis "Grupo profissional”, "Situação na profissão", "Rendimento mensal líquido", "Vínculo contratual” e "Extensão do horário semanal de trabalho" (exploradas de forma agregada recorrendo a uma análise de Correspondências Múltiplas e a uma Análise de Clusters) (Chaves e Morais, 2014) ${ }^{8}$. É um facto que tanto os resultados obtidos nesse estudo como os agora apresentados convergem num ponto: as tendências de homogeneização promovidas pela titulação académica e pela socialização escolar prolongada parecem mitigar, de forma significativa, o impacto das origens sociais na qualidade da inserção profissional dos diplomados da UL e da UNL no mercado de trabalho e, por essa via, nas dinâmicas de reprodução das desigualdades sociais. Esta propriedade niveladora merece ser assinalada pois raras vezes tem sido evidenciada pela sociologia portuguesa. Trata-se de um resultado que estimula e exige novos estudos que se libertem das fronteiras destas duas universidades e que se ampliem, desejavelmente, ao conjunto do sistema de ensino superior. Com efeito, é preciso não esquecer que nos debruçamos 
aqui sobre duas escolas particularmente bem cotadas no campo universitário português e, portanto, mais favoráveis a dinâmicas de nivelamento.

Em que medida esta conclusão poderá espelhar-se no conjunto global das universidades públicas? Em que medida poderá ou não ser perturbada se se introduzir também na equação os setores privado, concordatário, bem como o ensino politécnico? Eis um conjunto de quesitos que exigem análises posteriores, mas cuja resposta dificilmente poderá ser assegurada a breve trecho em virtude da inexistência de inquirições e indicadores de inserção profissional comuns e aplicados ao conjunto do sistema.

\section{Notas conclusivas}

O presente artigo pretendeu contribuir para o reforço em Portugal de uma linha de análise sobre a inserção de diplomados na qual se procura escrutinar o grau de incorporação dos diplomados no mercado de trabalho, bem como o acesso a posições vertical e horizontalmente (des)ajustadas na estrutura ocupacional, focalizando a observação nos "tempos de inserção". Com esse mesmo enfoque, o texto pretendeu concorrer para o esforço, ainda pouco ensaiado a nível nacional, de se observar as desigualdades entre diplomados, centrando a análise no momento da transição para o mercado de trabalho.

Relativamente ao primeiro aspeto constatou-se que, para uma clara maioria de licenciados na UL e UNL de 2004-2005, tanto a primo inserção como a obtenção de uma atividade adequada ao nível de estudos ou ao curso realizado decorreu de forma relativamente célere. Embora não seja possível generalizar, estes dados não podem também ser entendidos como uma mera exceção, pois convergem com os resultados de outros estudos que também abordaram universos de licenciados em universidades públicas, na primeira década deste século. É o caso dos supracitados estudos de Natália Alves, dos dados acerca dos graduados da Universidade de Évora que obtiveram os seus diplomas nos anos letivos de 2001-02 e 2005-06 (Vieira, Raposo, e Santos, 2008:6), entre os quais cerca de $41 \%$ obtiveram um emprego no período de 1 mês depois de terminarem o curso; ou ainda a situação dos licenciados da Universidade do Porto no ano letivo de 2005/06 (Gonçalves, Menezes, e Martins, 2009) - neste caso, a obtenção de um emprego depois da graduação tardou, em média, cerca de quatro meses (Ibidem: 49), com 59,9\% a considerem que "as funções desempenhadas no emprego atual só podiam ser executadas por alguém com a mesma licenciatura" (Ibidem: 19).

Apesar de estes dados não serem comparáveis, sugerem, no seu conjunto, que antes de 2011, ano em que a crise económica e financeira em que mergulhou a sociedade portuguesa se agravou de forma marcada, a inserção profissional de graduados do ensino superior era, como havia sublinhado Alves (2009: 29), "bem mais suave do que alguns discursos nos pretendem fazer querer", sendo 
pautada por níveis elevados de empregabilidade e de ajustamento profissional, quer vertical quer horizontal e por uma tendencial celeridade no acesso ao mercado de trabalho.

Quanto ao segundo propósito da análise, reforçaram-se hipóteses a que havíamos aportado noutras explorações dos mesmos dados, recorrendo a variáveis distintas (Chaves e Morais, 2014). Os resultados alcançados indiciam que os aspetos ligados às origens sociais não se traduziam, de forma nítida, em desigualdades no tempo de acesso a um emprego qualificante; por outras palavras, que estas duas universidades possuíam um papel de nivelamento social considerável dos seus licenciados no momento em que estes transitavam para o mercado de trabalho. Também este ponto de chegada não deixa de coincidir com as conclusões de outros estudos centrados na inserção de graduados, que procuraram igualmente examinar as relações entre posições familiares e desigualdades no momento da incorporação no mercado de trabalho. É o caso da análise realizada por Gonçalves (2000), no contexto da Universidade do Minho.

Concluímos reiterando uma cautela que havíamos expresso em texto anterior (Chaves e Morais, 2014): estas observações têm que ser interpretadas no quadro das universidades em que foram geradas, e cujas particularidades, favoráveis a dinâmicas niveladoras, já sublinhámos. Impõe-se agora acrescentar que, mesmo neste segmento universitário específico, essas observações poderão ter sido recentemente abaladas por uma dinâmica de retração do mercado de trabalho que, ao diminuir a oferta de oportunidades de trabalho e ao atenuar ou estancar um processo de mobilidade estrutural (Grácio, 1997) vivido pela sociedade portuguesa nas últimas décadas poderá trazer à colação, de forma mais nítida, o papel distintivo dos recursos familiares (nomeadamente daqueles que atuam sob a forma de "capital social”). Isto significa que, mesmo no contexto das duas universidades analisadas, o processo de nivelamento poderá ter sofrido um recuo que importa confirmar e acompanhar em termos longitudinais.

\section{Referências}

ALMEIDA, J.; e outros (2003), Diversidade na Universidade. Um Inquérito aos Estudantes de Licenciatura. Oeiras: Celta Editora.

ALMEIDA, J.; COSTA, A.; MACHADO, F. (1988), "Famílias, estudantes e universidade: painéis de observação sociográfica”. Sociologia, Problemas e Práticas, 4: 11-44.

ALVES, M. (2009), "Ensino superior, trabalho e emprego na actual sociedade de risco: um olhar sobre o caso de mestres e doutores". Sociologia, Problemas e Práticas, 59: 107-124.

ALVES, N. (2005), Trajectórias Académicas e de Inserção Profissional dos Licenciados pela Universidade de Lisboa 1999-2003. Lisboa: Universidade de Lisboa.

ALVES, N. (2009), Inserção profissional e Formas Identitárias. Lisboa: Educa.

ALVES, N. (2010), "Contributos para a delimitação do fim dos processos de inserção profissional”, in Ana Marques e Mariana Alves (coord.), Inserção profissional de graduados em Portugal. Braga: Húmus, 175-194. 
BALSA, C.; e outros (2001), Perfil dos Estudantes do Ensino Superior. Desigualdades $e$ Diferenciação. Lisboa: Colibri.

BERNARDI, F. (2012), "Social origins and inequality in educational returns in the labour market in Spain”. EUI Working Paper, 5: 1-31.

BUKODI, E.; GOLDTHORPE, J. (2011), "Social class returns to higher education: chances of access to the professional and managerial salariat for men in three British birth cohorts". Longitudinal and Life Course Studies, 2 (2): 185-201.

CARDOSO, J.; e outros (2014), "Employability and higher education in Portugal". Journal of Graduate Employability: 17-31.

CHAVES, M. (2010), Confrontos com o trabalho entre jovens advogados. As novas configurações da inserção profissional. Lisboa: ICS.

CHAVES, M.; MORAIS, C.; NUNES, J. (2009), "Os diplomados do ensino superior perante o mercado de trabalho: velhas teses catastrofistas, aquisições recentes”. Fórum Sociológico, 19: 83-98.

CHAVES, M.; NUNES, J. (2011), “As classes sociais já não contam? Advocacia e reprodução social”. Análise Social, 66: 49-70.

CHAVES, M.; MORAIS, C. (2014), "Nivelação e desigualdade na inserção profissional de diplomados do ensino superior”. Sociologia, Problemas e Práticas, 76: 87-108.

CHAVES, M.; ALVES, M.; MORAIS, C. (2013), Relatório sintese: Percursos de inserção profissional. Licenciados, Mestres e Doutores da UNL. Diplomados da coorte de 2010/11 em comparação com as coortes de 2004/05, 2008/9 e 2009/10. Lisboa: UNL.

COSTA, A. (1999), Sociedade de Bairro. Dinâmicas Sociais da Identidade Cultural. Oeiras: Celta Editora.

COSTA, A.; LOPES, J. (2010), “Desigualdades de percursos no ensino superior”, in Renato Carmo (org.). Desigualdades Sociais 2010: Estudos e Indicadores, Lisboa: Mundos Sociais, 145-152.

CRUZ, M.; CRUZEIRO, M. (1995), O Desenvolvimento do Ensino Superior em Portugal. Lisboa: DPGF.

GIRET, J-F. (2000), Pour une Économie de l'Insertion Professionnelle des Jeunes. Paris: CNRS.

GONÇALVES, C., MENEZES, I., \& MARTINS, M. (2009), Transição para o trabalho dos licenciados da Universidade do Porto (2005-2006). Porto: Universidade do Porto.

GONÇALVES, A. (2000), “A insustentável leveza da origem social. A inserção profissional dos licenciados da Universidade do Minho segundo o grau de instrução dos pais”. Revista Portuguesa de Educação, 13 (2): 157-174.

GRÁCIO, S. (1997), Dinâmicas de Escolarização e das Oportunidades Individuais. Lisboa: Educa.

HOUT, M. (1988), “More universalism, less structural mobility”. American Journal of Sociology, 93: 1358-1400.

INE (2014), Estatísticas do Emprego. Lisboa: INE.

MACHADO, F.; e outros (2003), "Classes sociais e estudantes universitários: origens, oportunidades e orientações”. Revista Crítica de Ciências Sociais, 66, 45-80.

MARQUES, A. P. (2006), Entre o Diploma e o Emprego: a inserção Profissional de Jovens Engenheiros. Porto: Afrontamento.

MARTINS, S. C.; MAURITTI, R.; COSTA, A. (2005), Condições Socioeconómicas dos Estudantes do Ensino Superior em Portugal. Lisboa: DGES/MCTES.

MASTEKAASA, A. (2011), "Social origins and labour market success: stability and change over Norwegian birth cohorts 1950-1969”. European Sociological Review, 27 (1): 1-15.

MAURITTI, R. (2003), “Caracterização e origens sociais”, in João Almeida e outros, Diversidade na Universidade, um Inquérito aos Estudantes de Licenciatura. Oeiras: Celta Editora, 13-30.

MORAIS, C. (2012), "Desigualdades sociais no trajecto académico e na inserção profissional: o caso dos licenciados na UL/UNL”, dissertação de mestrado, FCSH Universidade Nova de Lisboa, Lisboa. 
ODES - Sistema de Observação de Percursos de Inserção de Diplomados do ensino superior (2002), Inquérito de Percurso aos Diplomados do Ensino Superior: Síntese de Resultados. Lisboa: Instituto para a Inovação na Formação.

OPHEIM, V. (2007), "Equal opportunities? The effect of social background on transition from education to work among graduates in Norway". Journal of Education and Work, 20 (3): 255-282.

RADEMACHER, W.; LEITNER, M. (2009), Bologna Process in Higher Education in Europe. Key Indicators on the Social Dimension and Mobility. Luxemburgo: EC.

RAFFE, D. (2014), “Explaining national differences in education-work transitions”. European Societies, 16 (2): 175-193.

RAMOS, M.; PARENTE, C.; SANTOS, M. (2014), “Os licenciados em Portugal: uma tipificação de perfis de inserção profissional”. Educação e Pesquisa, São Paulo, 40 (2): 383-400.

RODRIGUES, M. L. (1999), Os Engenheiros em Portugal. Oeiras: Celta.

ROSE, J. (1998), Les jeunes face à l'emploi. Paris: Desclée de Brouwer.

STOREN, L. A.; ÅSE ARNESEN, C. (2007), "Winners and losers", in Jim Allen Rolf Van der Velden (ed.), Research into Employment and Professional Flexibility (REFLEX). Maastricht: Research Centre for Education and the Labor Market, 221-266.

TORCHE, F. (2011), "Is a college degree still the great equalizer? Intergenerational mobility across levels of schooling in the United States". American Journal of Sociology, 117 (3): 763-807.

TRIVENTI, M. (2011), “The role of higher education stratification in the reproduction of social inequality in the labour market: a comparative study of recent European graduates". MRPA Papper, 17: 1-35.

VINCENS, J. (1997), "L'insertion professionnelle des jeunes. À la recherche d'une définition conventionnelle”. Formation Emploi, 60: 21-36.

VIEIRA, C.; RAPOSO, L.; SANTOS, M. (2008), Relatório sobre o Inquérito aos Licenciados da Universidade de Évora. Évora: Pró-Reitoria para a Política da Qualidade e Inovação.

VERNIÈRES, M. (1997), L'insertion professionnelle: analyses et débats. Paris: Economica. 
